\title{
Haroldo de Campos, Camões e a Palavra-Máquina do Mundo
}

Diana Junkes Martha Toneto

(UNAERP - Universidade de Ribeirão Preto)

\begin{abstract}
RESUMO: NO POEMA A MÁQUINA DO MUNDO REPENSADA, HAROLDO DE CAMPOS REELABORA A ALEGORIA DA MÁQUINA DO MUNDO A PARTIR DA LEITURA QUE FAZ DOS GRANDES TEXTOS DO CÂNONE, FUNDINDO-OS AOS DILEMAS DA FÍSICA, SOBRETUDO AQUELES CONCERNENTES À ORIGEM DO UNIVERSO. INTERESSA-NOS O DIÁLOGO QUE CAMPOS ESTABELECE COM CAMÕES NO POEMA, MAIS ESPECIFICAMENTE, COM OS CANTOS V E X DE OS LUSÍADAS, DIÁLOGO ESTE QUE É MARCADO NÃO APENAS PELA EVIDENTE INTERTEXTUALIDADE, MAS QUE SE FUNDA NUM PROCESSO DE INVENÇÃO DE PRECURSORES.
\end{abstract}

ABSTRACT: IN THE POEM A MÁQUINA DO MUNDO REPENSADA, HAROLDO DE CAMPOS RECREATES THE WORLD MACHINE ALLEGORY FROM THE READING OF THE GREAT CANON TEXTS AND THE DISCUSSION OF THE PHYSICS' DILLEMAS, ESPECIALLY THOSE RELATED TO THE UNIVERSE ORIGIN. IN THIS STUDY WE ARE INTERESTED ON THE DIALOGUE WHICH CAMPOS ESTABLISHES IN THE POEM WITH CAMÕES, FOCUSING BOTH CANTO V AND X OF OS LUSÍADAS; DIALOGUE IN WHICH IS GROUNDED NOT ONLY BY THE EVIDENT INTERTEXTUALITY, BUT ALSO BASED IN THE PRECURSORS' INVENTION.

PALAVRAS-CHAVE: A MÁQUINA DO MUNDO REPENSADA, HAROLDO DE CAMPOS, INTERTEXTUALIDADE, POÉTICA SINCRÔNICA

KEYWORDS: A MÁQUINA DO MUNDO REPENSADA - HAROLDO DE CAMPOS - CAMÕES - INTERTEXTUALITY - SYNCHRONIC POETICS 


\section{historicidade da leitura em A Máquina do Mundo Repensada}

Pretendo aqui desenvolver algumas reflexões sobre o poema A Máquina do Mundo Repensada, de Haroldo de Campos, publicado em 2000. Mais especificamente, pretendo tratar da retomada da alegoria da máquina do mundo camoniana, por Haroldo, em seu poema, não apenas para marcar um diálogo que já fora estabelecido pelo poeta paulista com Camões em textos anteriores, mas também para levantar algumas perspectivas de leitura da obra do poeta a partir de sua postura em relação ao cânone, sempre relacionada com uma visão da história literária que ele mobiliza e que atua como o norte de seu processo criativo, marcado pela constante criação de precursores, pensada aqui em termos borgianos e também em termos de "make it new" poundiano.

Em A Máquina do Mundo Repensada, esse aspecto do processo criativo de haroldiano vem à tona de modo contundente. Pode-se dizer que o eu-poético, simulacro do próprio Haroldo, dialoga com a tradição literária, com a religião, com os mitos de criação e com a moderna física quântica em busca de respostas para a origem do universo ou, em visada mais ampla, poder-se-ia dizer que o poeta procura respostas para a sua própria origem, como, aliás, revelam alguns dos versos finais do poema: "sigo o caminho? busco-me na busca?". Entre a revisão do cânone e dos dilemas humanos a partir da ótica da física, A Máquina do Mundo Repensada espelha a leitura da história da tradição (não só a literária) feita por um poeta à procura da definição de seu ser e estar no mundo.

A Máquina do Mundo Repensada (de agora em diante, AMMR) é um longo poema, marcado da dicção épica tão cara ao poeta de campos e espaços. São ao todo 152 tercetos, mais uma coda de verso único, distribuídos em três cantos, orquestrados pelo rigor do decassílabo e pelo elaborado trabalho com a terzina. No primeiro canto é estabelecido, de modo explícito, o diálogo do poeta com outros "fabuladores" da máquina do mundo: Dante, Camões e Drummond. Além dessas três referências, outras surgem para revelar a grande erudição do poeta e o jogo de leitura que é estabelecido a partir da reconstrução da arqueografia da tradição que desafia o leitor desde os primeiros versos.

No segundo canto, o poeta volta-se para grandes dilemas da física, notadamente, aquele entre a física newtoniana e a einsteiniana. Mallarmé é seu guia nesse ponto da jornada, já que o acaso surge aqui como o grande operador do sentido da mensagem que é veiculada. No terceiro canto, depois de tanto 
ter percorrido, ou seja, depois de ter partido de Dante para chegar ao big bang, o poeta, de modo mais introspectivo, volta-se, sem abandonar os aportes dos cantos anteriores, para os mitos de criação e para os textos bíblicos lidos pelos midrashistas, sinalizando que o tempo todo esteve em busca de respostas para as suas origens, para o marco fundador de sua literatura que, conforme se apreende da leitura do texto, não passa somente pelo cânone literário, mas atravessa uma multiplicidade de referências, como é o caso da história e da filosofia, também presentes e atuantes no poema todo.

Como em um jogo de sucessivas etapas, estabelecem-se as jogadas de AMMR, em deslocamentos concêntricos, em torno de um núcleo que é o próprio poema, desdobrando-se nas partidas entre o poeta e aqueles que ele recria; entre o leitor e o poeta; entre o leitor e aqueles poetas recriados. Diante dessa complexidade, as chances do leitor contra o lance de dados do poema dependem da apreensão, nos labirintos do texto, da partida estabelecida entre o poeta e a herança da tradição que este assume e que dispõe no tabuleiro das jogadas-verso, ao fazer dos grandes poetas revisitados seus parceiros de jogo, os quais, por força da reinvenção, traduz, num movimento de double bind amplo, que diz respeito tanto às tensões entre a língua cultura de partida e a de chegada, como acontece com os textos dantescos e homéricos, quanto, no caso de escritores de nossa língua, a um modo de tradução que se edifica a partir da recriação das obras da tradição de língua portuguesa de modo semelhante àquele usado para verter textos de uma língua a outra.

O que me parece, portanto, é que Haroldo, ao estabelecer inúmeros diálogos em seu poema, amplia seus procedimentos de tradutor, de modo que podemos denominar transcriação, tradução como criação de nova informação estética (CAMPOS, H. 1992), não apenas os procedimentos tradutórios entre línguas, mas também aqueles intralinguais, realizados no interior do nosso idioma, por meio da leitura que o poeta faz de seus precursores, como é o caso, no poema em questão, de Camões, Sousândrade, Drummond, Rosa e outros.

A operação de transcriação, compreendida em amplo espectro, corrobora para o estabelecimento do caráter histórico do poema. De fato, a historicidade de AMMR é marcante, pois se constrói a partir da própria consciência que o leitor possui da consciência do poeta acerca da leitura/tradução da tradição realizada por este e que o leva, em abismo, à busca de sua origem, ou, talvez, de sua originalidade: “[...] a qualidade histórica do poema, a sua inevitável leitura 
palimpsesta, instila o sabor amargo da repetição e da dúvida acerca da originalidade" (BARBOSA, 1986, p. 15). Será possível inventar, fazer o novo? Em Haroldo, o novo dá-se, entre outros aspectos, sob o signo da (re)inscrição do cânone em seus poemas, dotados de alto grau de uma intertextualidade que, se de um lado, opera enigmas que exigem a re-cifração da tradição pelo leitor, ou ainda, a própria historicidade da leitura do leitor, para que possa re-cifrar a mensagem poética latente sob a força dos significantes, também desperta encantamento pela materialidade desses mesmos significantes que sustentam tais enigmas palimpsésticos.

As subdivisões prismáticas dessas várias referências impõem um movimento de leitura que acompanhe a construção do texto, profundamente marcado pela invenção da palavra poética que, naturalmente, dada a acentuada tentativa de conciliar o novo e o antigo, nasce da metalinguagem e de um barroquismo agudo. A palavra poética, tomada como mecanismo que engendra todos os questionamentos e diálogos apresentados, inclusive (e principalmente) aqueles concernentes a ela própria, é o cerne do jogo que se estabelece entre o leitor e o poeta, presentificado no texto através do eu-poético, que ao jogar também com os vários sujeitos poéticos dos textos do cânone revisitados, desenvolve, ao mesmo tempo, um percurso voltado aos temas centrais do diálogo, qual seja, a alegoria da máquina do mundo; e outro destinado à reelaboração metalingüística de cada fazer poético desses tantos parceiros, convertendo a máquina do mundo em máquina do poema. Para perceber a presença metalingüística de Camões em AMMR, é preciso, dada a força dos significantes, auscultar o ruído de fundo que orienta parte das engrenagens dessa máquina-poema.

\section{O mar e a fábula primeira}

Mesmo que os alísios camonianos soprem ao longo de toda a viagem empreendida pelo eu-poético haroldiano em AMMR, a presença de Os Lusíadas no poema surge de modo veemente na $8^{\mathrm{a}}$ estrofe, logo depois de o poeta defrontar-se com as feras dantescas, como se, ao deparar-se com elas, escolhesse, no lugar de enfrentá-las, buscar um novo guia para a sua jornada. O encontro com Camões não poderia dar-se de outra forma a não ser conver- 
gindo para o mar que, por força da atividade poética, é meio de articulação das imagens do mundo e do pensamento poético, uma vez que "Camões sempre pensa a poesia como o artifício que resulta de operações técnicas: para ele, o poema é, literalmente poiema, produto, controlado racionalmente []; a poesia em Camões é cosa mentale [...]" (HANSEN, In: NOVAES, 2005, p.165,171, grifos do autor).

Não é à toa, portanto, que João Alexandre Barbosa (2000), em Poesia e pensamento concreto, tenha aproximado Haroldo e Camões e, por intermédio dessa aproximação, tenha unido a máquina haroldiana ao maquinar do mundo camoniano. A máquina haroldiana, porém, exacerba no que concerne ao uso jogos sonoros e imagens, bem ao gosto cultista e conceptista, característico da poesia de Haroldo de Campos, conforme assinala Augusto de Campos:

Haroldo de Campos é por assim dizer um "concreto" barroco, o que o leva a trabalhar preferentemente com imagens e metáforas, que dispões em verdadeiros blocos sonoros. Nos fragmentos de "Ciropédia ou a Educação do Príncipe" (1952) merece menção o uso especial das palavras compostas, procurando converter a idéia em ideogramas verbais de som. (CAMPOS, A. apud CAMPOS, H. 2002, p.34).

Ainda que as diferenças entre as primeiras e as últimas obras do poeta manifestem-se sob diferentes aspectos, o jovem Haroldo de Ciropédia, mencionado por Augusto de Campos, é o mesmo de AMMR no que concerne ao trabalho com a linguagem nos poemas, já que esse tratamento do plano da expressão tem a ver com um modo de ser da poesia haroldiana, com seu ethos, orientado por um acento barroco, definido em termos de função poética de Jakobson, fortemente calcada na proximidade entre som e sentido. Daí a necessidade de ausculta do ruído de fundo camoniano:

8) - mas quisera também como o de ousada

fronte vasco arrostando - herói lusíada -

a adamastor: gigântea levantada

9) pavorosa figura - e não descria da

sua força o nauta diante do titã

mas com ele entestava qual na ilíada

10) héctor ao colossal ájax no afã 
de subjugá-lo em lide desigual

(e o mar açoita a nave capitã)

Vê-se aqui que a $8^{a}$ estrofe inicia-se pela adversativa "mas", dando a idéia de que haverá uma mudança em relação ao que vinha sendo dito. Até a $7^{\mathrm{a}}$ estrofe, o poeta vinha caminhando como Dante, mas, a partir da $8^{\mathrm{a}}$, passará a guiar-se por Camões. $\mathrm{Na} 8^{\mathrm{a}}$ estrofe, além da inversão, recorrente perturbação sintática que permeia vários versos do poema, a sonoridade de fronte vasco arrostando destaca-se pela força dos sons fricativos, vibrantes e sibilantes e sugere que o nauta terá de encarar mesmo grande perigo, assustador, marcado também pela assonância fechada de /o/. Ao surgir o gigante Adamastor, que poderia ser equiparado às feras de Dante, o eu-poético haroldiano abandona a atitude de paúra dantesca, para assumir a postura do Gama, encorajada pela força que os significantes do poema doam a ele. Diante de sua bravura levanta-se o gigante, prevalecem as nasais e o tom fantasmagórico e monstruoso como em gigantea e levantada. O gigante ergue-se do mar batendo na água, mas Vasco da Gama não se intimida diante da pavorosa figura, ainda mais amedrontadora pela abertura de /a/ e /o/, seguida da sombra imposta pelo /i/ e pelo / u/ de figura. Explodem também as aliterações, em / t/ e / d/, sugerindo o embate entre o ousado herói e o monstro (batendo, descria, nauta, diante, entestavam iliada). Não se pode deixar de notar aqui que essa sonoridade reverbera aspectos da sonoridade do Canto $\mathrm{V}$ de Os Lusíadas, em que se narra, justamente, o surgimento do Gigante Adamastor.

A dicção épica explicita-se nesse ponto de modo contundente. Para Jacyntho Lins Brandão (1990, p. 7), o épico é a costura de vozes, de épea. O aedo é aquele que transforma o vivido em canto e por isso garante que esse vivido se torne, efetivamente, acontecimento. Sem o canto, os feitos perder-se-iam; todavia, graças ao poder criativo do canto, eles permanecem porque o aedo atualiza-os, convocando, para cantar com ele, a Musa, que é mais do que a memória, posto ser filha de Zeus e Mnemosyne; ela é, portanto, fruto da ação do poder sobre a memória (ibid, id). A Musa já é, em si, criação de precursores: o que ela herda é mais do que eram, isoladamente, seus pais. A Musa é a soma (seletiva) de ambos, assim como é também soma a leitura de precursores empreendida por Haroldo de Campos em seu poema, de sorte que Homero, Dante, Camões, Drummond e todos os outros contemporanizam-se no discurso-canto de AMMR, porque 
Haroldo aedo é herdeiro dos discursos desses grandes poetas e traz na sua palavra, misto de memória e poder criativo, a arquipalavra da tradição que herdou e cuja influência administra ativamente.

A visada do aedo haroldiano é, portanto, da ordem da reflexão metalingüística: ao cantar os grandes poetas e seus poemas, os quais, no limite, são os grandes feitos e façanhas desses poetas, Haroldo, como um Orfeu bemsucedido (SCHÜLER, 1997), traz à luz e pereniza os poemas da tradição, não como foram (o Borges de Pierre Menard já nos ensinou que isso seria impossível), mas apenas como podem ser a partir da pulsão "make it new" que orienta o processo criativo de AMMR.

Voltemos ao poema. O final da $9^{a}$ estrofe introduz mais um diálogo com a tradição; este, porém, não é apenas haroldiano, mas a recriação do diálogo de Camões com o texto homérico, já que um dos elementos dialógicos do Canto $\mathrm{V}$ de Os Lusíadas é o episódio da luta de Heitor e Ájax na Ilíada. Além de recriar o diálogo camoniano, Haroldo de Campos não deixa de retomar aqui a sua própria leitura dos textos homéricos, ou seja, lê o Homero que Camões lê e também o Homero que traduz. A máquina do poema é, pois, palimpsesto do palimpsesto, de modo que, no corpo da escritura, o mar e sua travessia articulam a história literária e seu nutrimento em três momentos de viagem, o homérico, o camoniano e o haroldiano. Vale para AMMR o que Haroldo já havia dito em Sobre Finismundo:

O risco da criação [precisa ser] pensado como um problema de viagem e como um problema de enfrentamento com o impossível, uma empresa que, se por um lado é punida com um naufrágio, por outro é compensada com os destroços do naufrágio que constituem o próprio poema. (CAMPOS, 1996, p.15).

Quando o mar açoita a nave capitã, há o risco do naufrágio, há o risco do poema. É o que acontece em Finismundo, em que é narrada a última viagem de Ulisses. AMMR é fruto de outros naufrágios criativos, por isso, mais do que escombro, é a promessa de nova embarcação. Em seu navio, o poeta procura salvar os poemas legados pela tradição; procura tirá-los da condição de náufragos, para colocá-los na condição de sobreviventes a todo tipo de intempérie. Mas, ao salvar a linguagem dos poemas, pela superação do mar bravio, não pode impedir seu próprio naufragar. 
Não resistindo à aventura e à bybris, o poeta, resgatados os seus precursores, amarra-se ao mastro para ouvir o canto subversivo das sereias, que é o avesso do canto da Musa, pois o que cantam não tem fundo memorialístico, é pura invenção, (BRANDÃO, 1990, p.11), totalização do instante, já que não se apóia no passado. Assim preso, o poeta não pode evitar que o navio se parta entre Sila e Caríbdis; ainda bem, porque cada resto do casco é um pequeno espectro, que permite ao leitor o re-pensar (ou o re-inventar) do mundo pelo poema haroldiano. AMMR é destroço, mosaico, ou um coral onde se depositam alguns séculos da tradição, que o poeta viajor faz refletir no céu, como criação, é claro, mas criação orquestrada por invenção, canto dissonante que mistura Musa e sereias; por isso AMMR é, ao mesmo tempo, criação de precursores e invenção; releitura da tradição e comunicação estética com sabor de vanguarda.

Entre o escafandrista que vai às profundezas e o astronauta que vive em busca do devir, está o trajeto do cosmonauta do significante de AMMR e de sua poesia marcada por aquilo que ele denominava agoridade: uma poesia do tempo presente, crítica do "futuro e de seus paraísos sistemáticos", pósutópica, ou ainda utópica, porque engajada em um projeto de atualização constante do cânone, via operação tradutória e invenção. No caso de AMMR, esse desafio da totalidade do presente é o desafio da máquina do poema, a partir do repensar da máquina do mundo.

Haroldo de Campos, ao converter a sua tradição de leitura, mais até do que sua leitura da tradição, em releitura e nova escrita, engendra um canto babélico e ousadamente luciferino o qual, por não ter origem definida, faz Camões e Homero, por exemplo, falarem a mesma haroldiana língua, inventada pelo poeta, mas cravada pela aguda consciência da história, típica da poesia da modernidade, e desejosa da totalização e da ubiqüidade a que um "poema único", marcado de intertextualidade, para onde convergem todas as vozes e cantos, poderia dar acesso (BARBOSA, 1986). Observemos um pouco mais:

11) - quisera como o nauta fiel ao real

mandato no medonho oceano a rota

franqueando qual no breu brilha um fanal

$\mathrm{Na} 11^{\mathrm{a}}$ estrofe, o Canto $\mathrm{V}$ de Os Lusíadas ainda é o mote do diálogo estabelecido com Camões; os feitos de Vasco da Gama e sua incondicional 
obediência conduzem-no ao sucesso pelos mares "nunca d'antes navegados". Nessa estrofe são retomados os sons vibrantes e fricativos, presentes também na $8^{a}$ estrofe, e que sugerem, além dos significados ressaltados acima, a maneira como o capitão português conduzirá seu navio, abrindo vias no oceano: rotal franqueando qual no breu brilha um fanal. A sonoridade recria o marulho das águas do mar sob casco do navio criativo que eroticamente rasga a vulvaoceano como em Galáxias.

Seguindo sua jornada em companhia de Vasco da Gama, ou melhor, inserindo o seu caminho no caminho de Vasco da Gama, é concedido, ao eupoético, ver também a máquina do mundo. Nos primeiros versos da $11^{\mathrm{a}}$ estrofe, a profusão de paronomásias, entre assonâncias e aliterações, nauta, fiel, ao, real, mandato, medonho, oceano, a, rota, sugere uma circularidade que uma vez lida em conjunto com a estrofe seguinte parece corroborar a hipótese de que a máquina do mundo vem se aproximando, a girar.

Aqui se percebe que o espaço gráfico do poema, medido e quadriculado pelo rigor da forma fixa, parece vir abrigando as jogadas de um jogo de xadrez; a cada momento, uma jogada-verso antecipa ou pré-determina jogadasverso posteriores, de modo que signos em rotação são retomados, não apenas pelo enjambement freqüente, mas também pelos rastros dos significantes que parecem deslizar de um verso a outro, ora linearmente como as torres, ora diagonalmente como os bispos, ora aos saltos como os cavalos, ora como todos eles, ecoando aqui e ali, em mosaicos e xeque ao rei. Eis a máquina:

12) - quisera tal ao gama no ar a ignota

(camões o narra) máquina do mundo

se abrira (e a mim quem dera!) por remota

13) mão comandada - um dom saído do fundo

e alto saber que aos seres todos rege:

a esfera a rodar no éter do ultramundo

Na estrofe 12, a abertura assonante vista nos dois versos da $11^{\mathrm{a}}$ estrofe, cede, aos poucos, lugar para as nasais que também estavam presentes em mandato $e$ medonho. Nesse caso, a nasalização presente em gama, camões, mundo, mim, quem, mão, comandada, um, dom, fundo, ultramundo, e que circula pelo poema, evoca a própria imagem da máquina a girar: a esfera a rodar no éter (também presente n' 
Os Lusiadas, Canto X, estâncias 76 a 80). Retomando a leitura da $11^{\mathrm{a}}$ estrofe, a sonoridade tanto indica o movimento da nau sobre o mar como, pelo brilho sugerido pela imagem, pode ser o anúncio epifânico da máquina que irá surgir, a partir do verso seguinte, ou seja, a partir do primeiro verso da $12^{a}$ estrofe. Nas estrofes 14 e 15, a descrição da máquina ganha mais intensidade:

14) claro-amostrando os orbes e o que excede

na fábrica e no engenho a humana mente

(a cena se passando numa séde)

15)sidérea de esmeraldas e irrompente

chuveiro de rubis que a poderosa

mão divina ao redor - sumo- sapiente -

16) fizera constelar: e qual a rosa

toda se abre ao rocio que a toca e qual

desfolhada alcachofra antes zelosa

17) o entrefólio desnuda tal-e-qual

ao bravo gama a máquina se oferta

do mundo - e expõe-se ao olho de um mortal

A máquina abre-se como uma rosa que vai desabrochando, aos poucos, à medida que as assonâncias surgem nos versos da $16^{\mathrm{a}}$ estrofe e permanecem na $17^{\mathrm{a}}$ estrofe: qual, rosa toda se abre ao rocio que a toca e qual/ desfolhada alcachofra zelosa. Há, ainda, o parentesco sonoro entre rocio e rosa e toda e toca, que rimam toantemente. Esses jogos sonoros, a homofonia e a paronomásia, como a visão da máquina, exacerbam, por exemplo, em entrefólio e olho, gama e máquina.

Como a figura da rosa, a alcachofra, cujo centro e disposição das folhas lembra a descrição da máquina feita em Os Lusíadas (no Canto X, 81 "este orbe que, primeiro, vai cercando/ os outros mais pequenos que em si tem), remete, também, à analogia entre história literária e a alcachofra feita por Calvino: "O que conta para nós na obra literária é a possibilidade de continuar a desfolhá-la como uma alcachofra infinita, descobrindo dimensões de leituras sempre novas". (CALVINO, 2005, p.105).

Também Dias ([sd]), referindo-se ao poema de Haroldo de Campos, diz que, ao oferecer a imagem da rosa e da alcachofra, o poeta reinveste de significado uma antiga interpretação para a origem do universo dotado de uma erótica, 
dada pela filosofia chinesa, deflagrando "o mistério do universo no poema, acionado pela operação com a palavra” (ibid., p.10,11). A rosa que se abre diante do chuveiro de rubis é uma forma de concepção da arte poética que se volta sobre suas próprias engrenagens, ou melhor, sobre seu próprio corpo. A sobreposição de sons e a metáfora da rosa remetem à ubiqüidade da tradição no poema, que se vai abrindo e fazendo do texto um arquitexto instaurado por novidade pulsante. Daí por diante, a descrição da visão da máquina do mundo continua ainda por algumas estrofes, ancorada sempre na perspectiva de mundo camoniana, centrada no sistema ptolomaico, mas não apenas nele.

A valorização de toda construção humana que há em Camões, busca também (e talvez principalmente) a máquina do mundo na Ilíada, mais especificamente, no escudo de Aquiles, feito por Hefestos, o ferreiro dos deuses, o artesão laborioso (Iliada, Canto XVIII, p.257 a 265 da tradução de Haroldo de Campos). Diante de seu escudo, Aquiles deslumbra-se, pois não são elas factíveis por humanos e "nenhum ousa mirá-las de frente" (Ilíada, Canto XVIII, p.267). No escudo de Aquiles vê-se o universo, as regiões do mundo, assim como na descrição camoniana e na haroldiana:

22) mas se o gama a esquadrinha e nela (a déia

tétis o guiando) a vista logo inflama

de espanto e fundo abisma e afina a idéia

23) com aquilo que se vê em cosmorama

o empíreo esplendoroso e os sucessivos

céus nele orbitando à lata luz que os flama

[...]

29) por dentro acumulada num instante

e exultou: em geográfica cinese

iam-se as partes do mundo em desfilante

O escudo de Aquiles não comporta só a descrição do cosmos, equivale a ele; assim, a habilidade de Hefestos para forjar o escudo equivale à realização do poeta, criador do poema-máquina, fundador do cosmos poético, que ao girar faz ecoar as vozes que compõem os diálogos do texto, os quais, mais que conversa ou jogo de influências, são bordado. 


\section{Haroldo, Camões e outros parceiros de jogo}

A máquina do mundo repensada é a poesia-máquina do mundo repensada a partir do paideuma haroldiano. A disposição dos elementos da tradição em AMMR não é ingênua, tampouco aleatória, mas revela a maquinaria do poema, suas engrenagens, como se as estrofes fossem etapas de uma linha de montagem e cada etapa representasse uma parte da construção do produto final; o produto final, conseqüentemente, engloba as etapas iniciais. O que, entretanto, diferencia o poema dessa linha de montagem "fordista" é que as peças não são originais, não são fabricadas pelo poeta, mas ele as negocia numa bolsa de valores que ele mesmo institui ou, se quisermos, que ele mesmo inventa.

A novidade e a invenção do texto haroldiano residem no fato de ele dar novos usos a essas peças ancestrais, atualizando-as, para o leitor, por meio de sua poética sincronicamente articulada, como a esfera a rodar no éter do ultramundo. Quando evoca Camões, Haroldo evoca as leituras de Camões, o esforço laborioso do maquinar do mundo camoniano, que recria e a partir do qual inventa novos modos de ser de sua poética. Ao fazer isso, sua palavra funde o canto da Musa ao das sereias e transfere a maquinaria da linha de montagem para o navio, engendra viagem, navega, navega-nos. Como sabemos, navegar é sempre preciso, ainda que as rotas sejam árduas, ainda que seja árduo seguir a palvra-máquina do mundo de um poeta tão denso, tão intenso, em tabuleiro palimpsesto, palimp(incerto). A parceria vale a pena.

\section{Referência Bibliográfica}

BARBOSA, J.A. As Ilusões da Modernidade. São Paulo: Perspectiva, 1986.

. Poesia e pensamento concreto. In: Cult: Revista Brasileira de Literatura. São Paulo: Lemos Editorial, 2000, Ano IV, n.39, p.10-12.

BORGES, J. L. Kafka y sus precursores, In: Prosa Completa. Buenos Aires: Bruguera, 1982, vol.2, p. 226-228.

BRANDÃO, J. L. Do épos à epopéia: gênese dos poemas homéricos. Belo Horizonte: Sociedade Brasileira de Estudos Clássicos, nov. 1990, n.12.

CALVINO, I. O mundo é uma alcachofra. Por que ler os clássicos. São Paulo: Companhia das Letras, 1993, p. 205-207.

CAMÕES, L. V. Os Lusíadas. Lisboa: Ed. Ulisséia, 2002. 
CAMPOS, H. Da tradução como criação e como crítica. In: Metalinguagem e Outras Metas. São Paulo: Ed. Perspectiva, 1992, p. 31-48. . Sobre Finismundo: a última viagem. Rio de Janeiro: Sette Letras, 1996. . Poesia e modernidade: da morte do verso à constelação. O poema pós-utópico. In: O Arco Íris Branco. São Paulo: Ed. Imago, 1997, p. 243-270. . A Máquina do Mundo Repensada. São Paulo: Ateliê Editorial, 2000. Depoimentos de Oficina. São Paulo: Unimarco, 2002. .Galáxias. 2a ed. São Paulo: Ed. 34, 2004.

DIAS, M.H.M. Rotações poéticas da "Maquina do Mundo": de Camões a Haroldo de Campos. São José do Rio Preto: UNESP, mimeo.

HANSEN, J. A. A máquina do mundo. In: NOVAES, A. Poetas que pensaram o mundo. São Paulo: Companhia das Letras, 2005, p. 157-198.

HOMERO Ilíada Tradução Haroldo de Campos. Comentários e notas Trajano Vieira. São Paulo: Mandarim, 2001. Vols. 1 e 2.

SCHÜLER, D. Um lance de nadas na épica de Haroldo. Ponta Grossa: UEPG/ Museu Arquivo da Poesia Manuscrita, 1997. Col. Mapa.

TONETO, D.J.M. Convergências em A Máquina do Mundo Repensada: poesia e sincronia em Haroldo de Campos. Tese de Doutoramento. Araraquara: UNESP/ Faculdade de Ciências e Letras, 2008, 300p. 